Original article

\title{
ULTRASOUND MONITORING OF THE FIRST TRIMESTER OF PREGNANCY IN LOCAL GOATS THROUGH VISUALISATION AND MEASUREMENTS OF SOME BIOMETRIC PARAMETERS
}

\author{
M. KARADAEV ${ }^{1}$, I. FASULKOV ${ }^{1}$, N. VASSILEV ${ }^{1}$, Y. PETROVA ${ }^{2}$, \\ A. TUMBEV ${ }^{2} \&$ Y. PETELOV ${ }^{2}$
}

${ }^{1}$ Department of Obstetrics, Reproduction and Reproductive Disorders, ${ }^{2}$ Fifth year students; Faculty of Veterinary Medicine, Trakia University, Stara Zagora, Bulgaria

\section{Summary}

Karadaev, M., I. Fasulkov, N. Vassilev, Y. Petrova, A. Tumbev \& Y. Petelov, 2016. Ultrasound monitoring of the first trimester of pregnancy in local goats through visualisation and measurements of some biometric parameters. Bulg. J. Vet. Med., 19, No 3, 209-217.

The purpose of the present study was monitoring of the first trimester of pregnancy in local goats through ultrasound visualisation and measurements of some biometric parameters. Eighteen local Bulgarian goats, 2 to 4 years of age, weighing $48-56 \mathrm{~kg}$, reared in the Biobase of the Faculty of Veterinary Medicine - Stara Zagora were included in the experiments. All animals underwent ultrasound checks on gestation days $21,28,35,42$ and 49 . Ultrasound measurements included the following biometric parameters: uterine lumen diameter, crown-rump length, trunk diameter, biparietal diameter, inner and outer diameter of placentomes, long and short heart axis, foetal heart rate, foetal orbit diameter. The analysis of results indicated that ultrasound check during the first trimester of pregnancy of local goats could start at $21^{\text {st }}$ day of pregnancy when two biometric parameters were visualised - uterine lumen diameter $(10.3 \pm 2.7 \mathrm{~mm})$, filled with anechoic amniotic fluid and foetal crownrump length $(5.2 \pm 0.9 \mathrm{~mm})$, which was hyperechoic. From the $28^{\text {th }}$ day of gestation, ultrasound measurement of trunk diameter was possible. The inner and outer placentome diameters, biparietal diameter and foetal heart rate could be used for monitoring of pregnancy by the end of the first trimester (days 42 and 49).

Key words: goats, monitoring, pregnancy, ultrasound biometry

\section{INTRODUCTION}

The ultrasonography is a rapid, accurate non-invasive method, used in routine practice for monitoring and control of reproduction in small ruminants. The ultrasound check of pregnancy is a contemporary element of routine reproduction management of animals and therefore, an integral part of modern reproduction technologies (Medan \& Abd El-Aty, 2010). The main practical applications of the method in small ruminant reproduction include early pregnancy diagnostics, mo- 
nitoring of embryo-foetal development, determination of the number and sex of offspring (Abdelghafar et al., 2007; Santos et al., 2007; Yotov, 2007; 2011; Karen et al., 2009).

At a global scale, numerous reports outlining the ultrasonography as a main element of pregnancy monitoring in goats are available. The possibilities offered by echography make it a valuable accessible practical method for monitoring of embryo-foetal development. When the time of insemination is unknown, ultrasound pregnancy check allows determining the gestation age with respect to the proper prenatal management (Karen et al., 2003; Lee et al., 2005), adequate and timely determination of the dry period duration and identification of the tentative parturition date (Doize et al., 1997; Karen et al., 2001; 2009).

The embryo-foetal development and gestational age assessment via ultrasound examination has been reported in different animal species - sheep (González de Bulnes et al., 1998; Azevedo et al., 2007), cows (Hunnam et al., 2009), llamas (Gazitúa et al., 2001), musk oxen (Pharr et al.,1994), buffaloes (Ali \& Fahmy, 2007), mouflons (Santiago-Moreno et al., 2005), sika deer (Yanagawa et al., 2009) и др.

In goats, ultrasound imaging of different criteria for pregnancy monitoring and measurements of respective parameters was mainly used for gestation age evaluation (Medan et al., 2004; Sugana et al., 2008; Amer, 2010; Nwaogu et al., 2010; Abdelghafar et al., 2011; Airina et al., 2011). To our best knowledge, there are no data reporting ultrasound monitoring of pregnancy in local goats.

The purpose of the present study was to perform ultrasound visualisation and biometry of several parameters during the first trimester of pregnancy in local goats.

\section{MATERIALS AND METHODS}

\section{Experimental animals}

The experiment was approved by the Animal Ethics Committee at the Faculty of Veterinary Medicine, Trakia University - Stara Zagora in accordance to Ordinance 20/1 November 2012 of the Bulgarian Ministry of Agriculture and Food.

In this study, 18 local Bulgarian goats, 2 to 4 years of age, weighing $48-56 \mathrm{~kg}$, reared in the Biobase of the Faculty of Veterinary Medicine - Stara Zagora were used. Goats were between $1^{\text {st }}$ and $3^{\text {rd }}$ lactation, manually milked twice daily (morning and evening). Their ration consisted of grass and alfalfa hay, pelleted concentrated feed (corn, wheat, barley, sunflower meal, vitamin and mineral premix); water was offered freely.

The experiment started by the end of August. The oestrus in goats was synchronised by intravaginal sponges (Syncropart ${ }^{\circledR}$, Seva Sante Animale). By the $12^{\text {th }}$ day, sponges were removed and the goats were injected i.m. with 500 IU PMSG (Folligon $\AA$, MSD Animal Health). They were mated twice with a fertile male breeder between the $24^{\text {th }}$ and $48^{\text {th }}$ hours after sponge removal.

\section{Equipment}

The examination was done with SonoScape A5V® ultrasound (SonoScape, China) and multifrequency (5.0-12.0 $\mathrm{MHz}$ ) linear transducer. Two approaches were used - transrectal (until the $35^{\text {th }}$ day of gestation) and transabdominal (after the $35^{\text {th }}$ day) in standing position (Yotov, 2007). Ultrasound transmission Aqua Ultra Clear gel (Ultragel, Hungary) was used to facilitate visualisation. Ultrasound criteria for early pregnancy were visualisation of enlarged uterine lumen, filled with 
anechoic amniotic fluid and presence of hyperechoic embryo.

\section{Experimental design}

All goats were submitted to a single ultrasound check at 7-day intervals: on gestation days $21,28,35,42$ and 49 and measurement of the following biometric parameters: uterine lumen diameter, crownrump length, trunk diameter, biparietal diameter, foetal orbit diameter, inner and outer diameter of placentome, long and short heart axis, foetal heart rate.

The ultrasound measurements of studied parameters was done according to the description of Amer (2008), with some modifications. The crown-rump length was determined from the top of the skull to the end of sacrum of a fully extended foetus. Trunk diameter was measured through the biggest transverse abdominal section. Biparietal diameter was measured meeting the following criteria: the cerebral falx midline divided the hemispheres into two equidistant parts and the measurement was taken from the outer surface of the proximal calvarium to the inner surface of distal calvarium (Amer, 2008).
Outer and inner placentome diameters were measured on 3 placentomes and the results were averaged. Foetal orbit diameter, long and short heart axis were measured as transverse sections in a longitudinal foetal position. Foetal heart rate was determined through echocardiography, in B-M mode and calculated by the software. Data were presented as mean and standard deviations (SD).

\section{RESULTS}

The first visualisation of enlarged uterine lumen filled with anechoic amniotic fluid and presence of hyperechoic embryo in all studied goats $(n=18)$ occurred on the $21^{\text {st }}$ day after mating.

Average values $( \pm \mathrm{SD})$ of studied biometric parameters are shown on Table 1 .

On the $21^{\text {st }}$ day of gestation, two biometric parameters could be visualised and measured: uterine lumen diameter and embryo length (Fig. 1), with average values of $10.3 \pm 2.7$ and $5.2 \pm 0.9 \mathrm{~mm}$ respectively. The measurements of both parameters was possible during the entire first trimester of pregnancy. After the $35^{\text {th }}$ day

Table 1. Ultrasound measurements (mean $\pm \mathrm{SD}, \mathrm{n}=18$ ) of studied biometric parameters in goats during the first trimester of pregnancy

\begin{tabular}{|c|c|c|c|c|c|}
\hline \multirow{2}{*}{ Biometric parameters } & \multicolumn{5}{|c|}{ Gestation day } \\
\hline & 21 & 28 & 35 & 42 & 49 \\
\hline Uterine lumen diameter, $\mathrm{mm}$ & $10.3 \pm 2.7$ & $19.0 \pm 3.3$ & $28.8 \pm 3.9$ & $42.8 \pm 4.9$ & $54.2 \pm 4.5$ \\
\hline Crown-rump length, mm & $5.2 \pm 0.9$ & $19.3 \pm 2.0$ & $20.3 \pm 1.6$ & $32.8 \pm 2.6$ & $45.6 \pm 2.9$ \\
\hline Trunk diameter, $\mathrm{mm}$ & - & $6.8 \pm 0.9$ & $9.9 \pm 1.1$ & $14.3 \pm 2.7$ & $18.8 \pm 1.1$ \\
\hline Biparietal diameter, $\mathrm{mm}$ & - & - & - & $9.4 \pm 1.1$ & $13.8 \pm 0.7$ \\
\hline Foetal orbit diameter, $\mathrm{mm}$ & - & - & - & - & $6.5 \pm 0.5$ \\
\hline $\begin{array}{l}\text { Outer placentome } \\
\text { diameter, } \mathrm{mm}\end{array}$ & - & - & - & $9.3 \pm 1.1$ & $13.6 \pm 1.8$ \\
\hline $\begin{array}{l}\text { Inner placentome } \\
\text { diameter, mm }\end{array}$ & - & - & - & $3.8 \pm 0.7$ & $5.7 \pm 0.6$ \\
\hline Foetal heart rate, $\min ^{-1}$ & - & - & $212.5 \pm 6.1$ & $210.0 \pm 4.0$ & $210.4 \pm 7.3$ \\
\hline Long heart axis, mm & - & - & - & - & $6.1 \pm 1.1$ \\
\hline Short heart axis, $\mathrm{mm}$ & - & - & - & - & $4.4 \pm 0.7$ \\
\hline
\end{tabular}




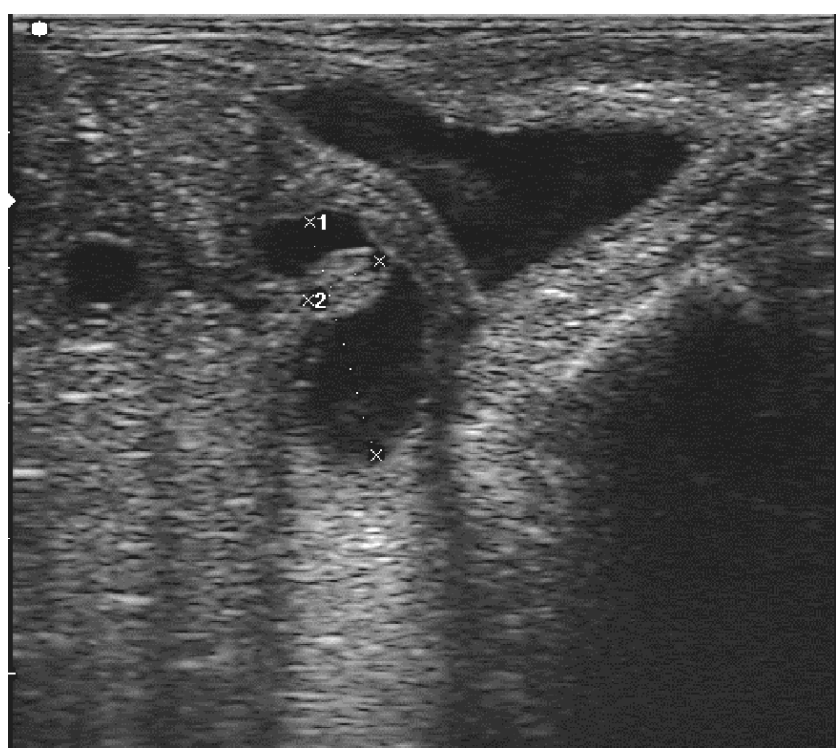

Fig. 1. Ultrasound measurement of uterine lumen diameter (1) and embryo's length (2) in a goat on the $21^{\text {st }}$ day of gestation.

of gestation, the anterior and posterior parts of the embryo could be already distinguished and allowed measuring of crown-rump length until the end of the study (Fig. 2A).

Trunk diameter (Fig 2A) was first determined by ultrasonography on the $28^{\text {th }}$ gestation day $(6.8 \pm 0.9 \mathrm{~mm})$ and by the end of the first trimester of pregnancy its average value was $18.8 \pm 1.1 \mathrm{~mm}$.

Foetal biparietal diameter (Fig. 2B) was seen and measured by the $42^{\text {nd }}(9.4 \pm$ $1.1 \mathrm{~mm})$ and $49^{\text {th }}$ day of pregnancy $(13.8 \pm 0.7 \mathrm{~mm})$. Foetal orbit diameter could be determined by ultrasound examination on the $49^{\text {th }}$ day of pregnancy and averaged $6.5 \pm 0.5 \mathrm{~mm}$.

By the end of the first trimester of pregnancy (days 42 and 49), the placentome dimensions - outer and inner diameters - could be measured (Fig. 2C).

The average foetal heart rate $\left(212.5 \pm 6.1 \mathrm{~min}^{-1}\right)$ was registered by echocardiography for the first time on the $35^{\text {th }}$ gestation day (Fig. 2D).
The ultrasound measurement of long and short heart axis (Fig. 3) was possible by the end of the first trimester of pregnancy $\left(49^{\text {th }}\right.$ day) and respective average values were $6.1 \pm 1.1 \mathrm{~mm}$ and $4.4 \pm 0.7 \mathrm{~mm}$.

\section{DISCUSSION}

The analysis of results showed that the ultrasound monitoring of the first trimester of pregnancy in local goats could possibly start on the $21^{\text {st }}$ day of gestation, when two biometric parameters could be observed and quantitated - diameter of the uterine lumen, filled with anechoic amniotic fluid and the length of the hyperechoic embryo. The average uterine lumen diameter at that time of the pregnancy was $10.3 \pm 2.7 \mathrm{~mm}$. Similar data in dairy goats are reported by Amer (2010), who established the embryonic vesicle for the first time by gestation day $19.5 \pm 0.3$ with transverse diameter of about $10 \mathrm{~mm}$. A finding of a similar size, but by the $21^{\text {st }}$ day of 
gestation, was reported by Padilla-Rivas et al. (2005) in Boer goats. Unlike these data, the embryonic vesicle was observed by Suguna et al. (2008) on the $28^{\text {th }}$ day of pregnancy. The differences in the time of visualisation and the average size of this parameter were probably due to goat breed-related differences, the number of foetuses, the type and frequency of the ultrasound transducer.

The measurement of the crown-rump length of the foetus in our study showed considerable increase in average values with progression of pregnancy. A similar trend was found for the trunk diameter,
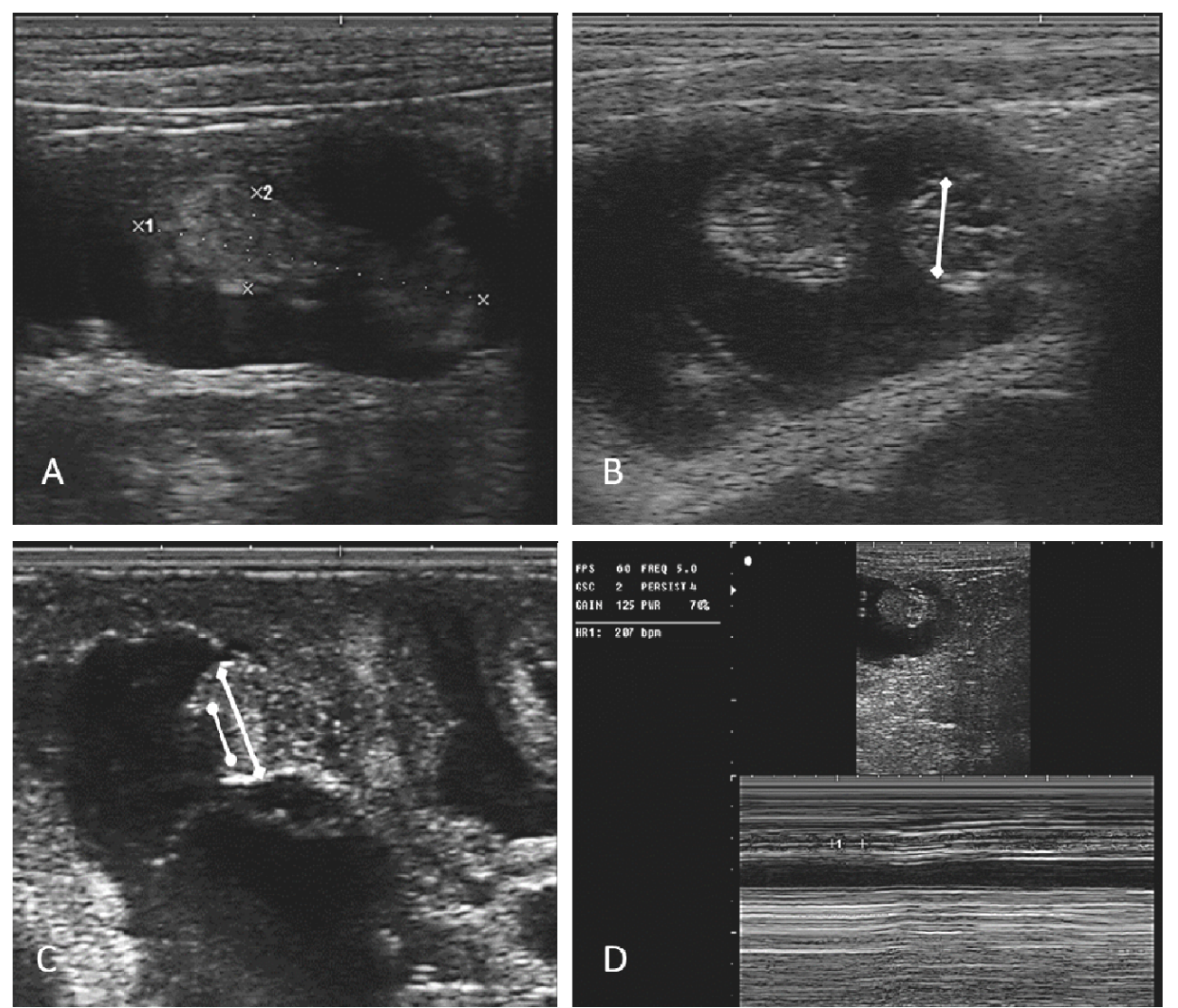

Fig. 2. Ultrasound biometry on the $42^{\text {nd }}$ day of gestation in a goat: A. crown-rump length (1); trunk diameter (2); B. foetal biparietal diameter (arrow); C. outer and inner placentome diameters (arrows); D. foetal heart rate (B-M mode).

BJVM, 19, No 3 


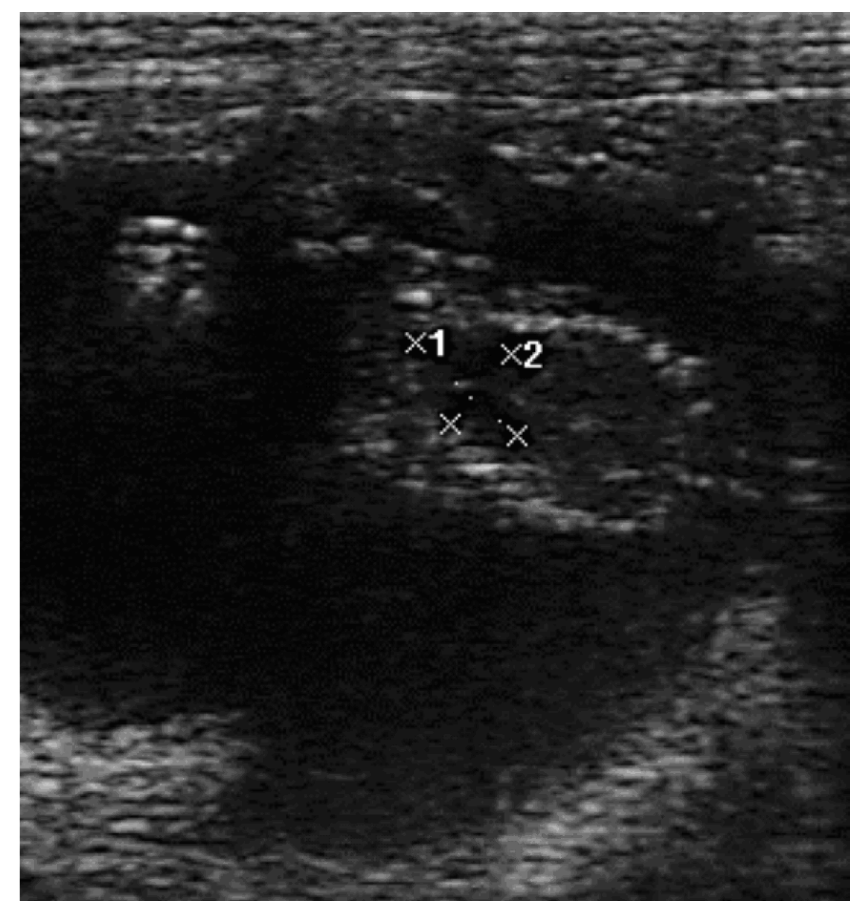

Fig. 3. Ultrasound measurements of the long (1) and short (2) foetal heart axis on the $49^{\text {th }}$ day of gestation in a goat.

observed in Egyptian local goats between gestation days 40 and 140 by Karen et al. (2009).

The visualisation and measurement of the biparietal diameter, outer and inner placentome diameter in local goats was possible by the $42^{\text {nd }}$ and $49^{\text {th }}$ gestation days, whereas the foetal orbit diameter was quantitated only on the $49^{\text {th }}$ day. The analysis of results showed that these parameters could be hardly used for monitoring of the first trimester of pregnancy in Bulgarian local goats. Comparably, a number of researchers established a very strong correlation between gestational age and biparietal diameter during the second trimester of pregnancy (Abdelghafar et al., 2007; 2011; Amer, 2008; 2010). Abdelghafar et al. (2007), affirmed that biparietal diameter was difficult for measuring after the $95^{\text {th }}$ day of pregnancy because of the marked growth of the foetus and the compression of the head by other foetal body parts. Also, the non-static position and posture of the foetus impede the proper scanning of the head and biparietal diameter measurement observed in different goat breeds (Toggenburg, Nubian, Angora) during the $2^{\text {nd }}$ trimester of pregnancy (Haibel et al., 1989). That is why Lee et al. (2005) reported a significant correlation $\left(\mathrm{P}<0.05 ; \mathrm{R}^{2}=0.8089\right)$ between gestational age and biparietal diameter in Korean black goats between the $60^{\text {th }}$ and $135^{\text {th }}$ gestation day. Abdelghafar et al. (2011) determined the parameter in Saanen goats from the $6^{\text {th }}$ week of gestation until the end of pregnancy providing proof about a strong correlation with gestational age $\left(\mathrm{P}<0.01 ; \mathrm{R}^{2}=0.91\right)$.

For accurate determination of the biparietal diameter, the head of the foetus 
should be scanned in a transverse axial plane. The symmetrical imaging is essential for a proper measurement, and symmetry is identified by the simultaneous visualisation of both foetal eye orbits (Lee et al., 2005). Nwaogu et al. (2010) reported that the foetal orbit diameter was a relevant index for determination of gestation stage in Red Sokoto goats, observing a statistically significantly strong correlation $\left(\mathrm{R}^{2}=0.92 ; \mathrm{P}<0.001\right)$ with gestational age between the $57^{\text {th }}$ and $124^{\text {th }}$ days. According to the authors, the determination of the foetal orbit diameter was not a consistent parameter for gestational age evaluation during the last trimester of pregnancy, as during that period, the growth rate of the foetal orbit was relatively low unlike the second trimester, when foetal orbit grows relatively rapidly.

The initial visualisation of placentomes and the biometry of the outer and inner placentome diameters in local goats was possible by the $42^{\text {nd }}$ day of gestation. The established average outer diameter of $9.3 \pm 1.1 \mathrm{~mm}$ was comparable to values obtained by Suguna et al. (2008). Some authors believe that the clear ultrasound visualisation of placentomes in goats occurs from the middle of the first to the end of the second trimester of pregnancy (Doize et al., 1997; Suguna et al., 2009). For a most consistent result, the average value of 2 to 5 placentome diameters is retained (Doize et al., 1997; Lee et al., 2005), and in the belief of Karen et al. (2009) only the dimensions of the biggest placentomes correlated strongly with gestational age.

In studied goats, heart activity was detected by the $28^{\text {th }}$ day of gestation, and foetal heart rate in B-M mode of the scanner was measured for the first time by the $35^{\text {th }}$ day. The average values of this biometric parameter were similar during the three measurement periods $(35,42$ and 49 days of gestation) and the highest heart rate was registered by the $35^{\text {th }}$ day $\left(212.5 \pm 6.1 \mathrm{~min}^{-1}\right)$ while by the end of the first trimester of pregnancy it was $210.4 \pm$ $7.3 \mathrm{~min}^{-1}$. The reduction of foetal heart rate with advancing of the pregnancy in goats was also reported by other researchers (Martinez et al., 1998; Karen et al., 2009).

The visualisation of the foetal heart and the ultrasound measurements of the long and short axes of the heart in local goats was possible by the $49^{\text {th }}$ day of gestation. Airina et al. (2011) have measured foetal heart from the $9^{\text {th }}$ week of gestation until the parturition to prove that this parameter was reliable for evaluation of gestational age in goats. According to Lee et al. (2005), heart axes should be measured after simultaneous visualisation of foetal atria and ventricles in transverse section view, during the diastole and immobile foetus. We also affirm that this parameter is useful for monitoring of the second and third trimesters of goat pregnancy.

In conclusion, the analysis of all data indicated that ultrasound foetal biometry in local Bulgarian goats could start on the $21^{\text {st }}$ day of gestation when at least two parameters are clearly visualised and could be measured - uterine lumen diameter and crown-rump length. From the $28^{\text {th }}$ day onward, trunk diameter was already detectable. The outer and inner placentome diameters, biparietal diameter and foetal heart rate could be used for ultrasound pregnancy monitoring by the end of its first trimester $-42^{\text {nd }}$ and $49^{\text {th }}$ days of gestation.

\section{ACKNOWLEDGMENTS}

The present study was funded by Project 19/2013 of the Faculty of Veterinary Medicine, Trakia University, Stara Zagora, Bulgaria. 
Ultrasound monitoring of the first trimester of pregnancy in local goats through visualisation ...

\section{REFERENCES}

Abdelghafar, R. M., A. O. Bakhiet \& B. H. Ahmed, 2007. B-mode real-time ultrasonography for pregnancy diagnosis and fetal number in Saanen goats. Journal of Animal and Veterinary Advances, 6, 702705.

Abdelghafar, R. M., B. H. Ahmed, M. T. Ibrahim \& P. Mantis, 2011. Prediction of gestational age by transabdominal realtime ultrasonographic measurements in Saanen goats (Capra hircus). Global Veterinaria, 6, 346-351.

Airina, R. K. R. I., A. R. M. Nizam, R. B. Abdullah \& W. E. W. Khadijah, 2011. Using fetal-heart size measured from ultrasound scanner images to estimate age of gestation in goat. Journal of Animal and Veterinary Advances, 10, 2528-2540.

Ali, A. \& S. Fahmy, 2007. Ultrasonographic fetometry and determination of fetal sex in buffaloes (Bubalus bubalis). Animal Reproduction Science, 106, 90-99.

Amer, H. A, 2008. Determination of first pregnancy and foetal measurements in Egyptian Baladi goats (Capra hircus). Veterinaria Italiana, 44, 429-437.

Amer, H. A., 2010. Ultrasonographic assessment of early pregnancy diagnosis, fetometry and sex determination in goats. Animal Reproduction Science, 117, 226-231.

Azevedo, E. M. P., C. R. Aguiar Filho, L. M. Freitas Neto, M. C. Rabelo, M. H. B. Santos, P. H. Lima, V. J. F. Freitas \& M. A. L. Oliveira, 2007. Ultrasound fetal measurement parameters for early estimate of gestational age and birth weight in ewe. Medicina Veterinaria, 1, 56-61.

Doize, F., D. Vaillancourt, H. Carabin \& D. Bélanger, 1997. Determination of gestational age in sheep and goats using transrectal ultrasonographic measurement of placentomes. Theriogenology, 48, 449-460.

Gazitúa, F. J., P. Corradini, G. Ferrando, L. A. Raggi \& V. H. Parraquez, 2001. Prediction of gestational age by ultrasonic fetometry in llamas (Lama glama) and al- pacas (Lama pacos). Animal Reproduction Science, 66, 81-92.

González de Bulnes, A., J. S. Moreno \& A. L. Sebastián, 1998. Estimation of fetal development in Manchega dairy ewes by transrectal ultrasonographic measurements. Small Ruminant Research, 27, 243-350.

Haibel, G. K., N. R. Perkins \& G. M. Lidl, 1989. Breed differences in biparietal diameters of second trimester in Toggenburg, Nubian and Angora goat fetuses. Theriogenology, 32, 827-834.

Hunnam, J. C., T. J. Parkinson, N. LopezVillalobos \& S. McDougall, 2009. Association between gestational age and bovine fetal characteristics measured by transcutaneous ultrasound over the right flank of the dairy cow. Australian Veterinary Journal, 87, 379-383.

Karen, A. M., El-S. M. Fattouh \& S. S. AbuZeid, 2009. Estimation of gestational age in Egyptian native goats by ultrasonographic fetometry. Animal Reproduction Science, 114, 167-174.

Karen, A., J. F. Beckers, J. Sulon, N. M. de Souza, K. Szabados, J. Reczigel \& O. Szenci, 2003. Early pregnancy diagnosis in sheep by progesterone and pregnancy associated glycoprotein tests. Theriogenology, 59, 1941-1948.

Karen, A., P. Kovács, J. F. Beckers \& O. Szenci, 2001. Pregnancy diagnosis in sheep: review of the most practical methods. Acta Veterinaria Brno, 70, 115-126.

Lee, Y., O. Lee, J. Cho, H. Shin, Y. Choi, Y. Shim, W. Choi, H. Shin, D. Lee, G. Lee \& S. Shin, 2005. Ultrasonic measurements of fetal parameters for estimation of gestational age in Korean black goats. Journal of Veterinary Medical Science, 67, 497-502.

Martinez, M. F., P. Bosch \& R. A. Bosch, 1998. Determination of early pregnancy and embryonic growth in goats by transrectal ultrasound scanning. Theriogenology, 49, 1555-1565.

Medan, M. S. \& A. M. Abd El-Aty, 2010. Advances in ultrasonography and its application in domestic ruminants and other 
farm animals reproduction. Journal of $\mathrm{Ad}$ vanced Research, 1, 123-128.

Medan, M., G. Watanabe, G. Absy, K. Sasaki, S. Sharawy \& K. Taya, 2004. Early pregnancy diagnosis by means of ultrasonography as a method of improving reproductive efficiency in goats. Journal of Reproduction and Development, 50, 391-397.

Nwaogu, I. C., K. O. Anya \& P. C. Agada, 2010. Estimation of foetal age using ultrasonic measurements of different foetal parameters in red Sokoto goats (Capra hircus). Veterinarski Arhiv, 80, 225-233.

Padilla-Rivas, G. R., B. Sohnrey \& W. Holtz, 2005. Early pregnancy detection by realtime ultrasonography in Boer goats. Small Ruminant Research, 58, 87-92.

Pharr, J. W., J. E. Rowell \& P. F. Flood, 1994. Fetal growth in musk oxen determined by transabdominal ultrasonography. Canadian Journal of Veterinary Research, 58, 167-172.

Santiago-Moreno, J., A. González-Bulnes, A. Gómez-Brunet, A. Toledano-Diaz \& A. López-Sebastián, 2005. Prediction of gestational age by transrectal ultrasonographic measurements in the mouflon (Ovis gmelini musimon). Journal of Zoo and Wildlife Medicine, 36, 457-462.

Santos, M. H. B., M. C. Rabelo, S. I. Guido, J. N. C. Torreão, E. S. Lopes Júnior, V. J. F. Freitas, P. F. De Lima \& M. A. L. Oliveira, 2007. Determination of the genital tubercle migration period in Morada Nova sheep foetuses by ultrasonography. Reproduction in Domestic Animals, 42, 214-217.

Suguna, K., S. Mehrotra, S. K. Agarwal, M. Hoque, S. K. Singh, U. Shanker \& T. Sarath, 2008. Early pregnancy diagnosis and embryonic and fetal development using real time B mode ultrasound in goats. Small Ruminant Research, 80, 80-86.
Suguna, K., S. Mehrotra, S. K. Agarwal, M. Hoque, U. Shanker, S. K. Singh \& V. P. Varshney, 2009. Effect of exogenous insulin administration on ovarian function, embryo/fetal development during pregnancy in goats. Animal Reproduction Science, 111, 202-213.

Yanagawa, Y., Y. Matsuura, M. Suzuki, S. Saga, H. Okuyama, D. Fukui, G. Bandou, S. Katagiri, Y. Takahashi \& T. Tsubota, 2009. Fetal age estimation of Hokkaido sika deer (Cervus nippon yesoensis) using ultrasonography during early pregnancy. Journal of Reproduction and Development, 55, 143-148.

Yotov, S., 2007. Early pregnancy diagnostics and determining the number and sex of fetuses in sheep. PhD thesis, Stara Zagora (BG) .

Yotov, S., 2011. Application of two-dimensional (B-mode) ultrasonography in sheep reproduction. Kota Print, Stara Zagora (BG).

Paper received 17.03.2015; accepted for publication 15.06.2015

\section{Correspondence:}

Manol Karadaev, DVM

Department of Obstetrics, Reproduction and Reproductive Disorders,

Faculty of Veterinary Medicine,

Trakia University, 6000 Stara Zagora, Bulgaria e-mail:karadaev@abv.bg 